\title{
O HORIZONTE LOGÍSTICO AMAZÔNICO: UMA VISÃO DOS PROCESSOS FRAGMENTADOS DE RESIDUOS EM MANAUS
}

\section{THE AMAZON LOGISTIC HORIZON: A VIEW OF THE FRAGMENTED PROCESSES OF WASTE IN MANAUS}

\author{
Elane de Souza Mafra \\ Tássia Patricia Silva do Nascimento \\ Marcos Carneiro da Silva
}

\section{RESUMO}

O presente trabalho tem como objetivo estudar a logística reversa e sua aplicação, para amenizar o risco das garrafas de PET - Politereftalato de Etileno, descartadas de forma incorreta na orla da zona urbana de Manaus. Sendo Logística Reversa um conceito muito amplo, significando todas as operações relacionadas com a reutilização de produtos e materiais, o trabalho concentra-se no exame dos fluxos reversos, ou seja, naqueles que fluem no sentido inverso ao da cadeia direta, a partir dos produtos descartados, após seu consumo, visando agregar valor de diversas naturezas, por meio da reintegração de seus componentes ou materiais constituintes ao ciclo produtivo. Como fundamentação teórico-conceitual, o estudo recorre à discussão sobre o meio ambiente, as políticas públicas e o alcance da logística reversa, analisando as estratégias para estruturação da cadeia de reciclagem. A pesquisa adotada é de caráter exploratório, com aplicação de diferentes estratégias para a coleta de dados, envolvendo fontes secundárias produzidas por órgãos públicos, instituições especializadas e mídia. Os resultados apontam que os múltiplos atores envolvidos em todo processo da cadeia reversa do PET, seja público ou privado, não consegue individualmente organizar-se para o alcance da efetividade operacional e ambiental desejável na cidade de Manaus, apesar do avanço no volume de reciclagem. $\mathrm{O}$ alcance de bons resultados depende, sobretudo, do investimento nos dois extremos da cadeia reversa: na coleta seletiva e no mercado para o produto reciclado, passando por alternativas de soluções que promovam mudança cultural dos ribeirinhos no sentido de reeducá-los quanto ao uso e descarte corretos das garrafas PET.

PALAVRAS-CHAVE: Logística Reversa, Embalagem de PET, Impacto Ambiental, Meio Ambiente. 


\section{ABSTRACT}

The present work aims to study reverse logistics and its application, in order to mitigate the risk of PET bottles - Ethylene Polyetherephthalate, incorrectly discarded on the edge of the urban area of Manaus. As Reverse Logistics is a very broad concept, meaning all operations related to the reuse of products and materials, the work focuses on examining the reverse flows, that is, those that flow in the opposite direction to the direct chain, from the products discarded, after their consumption, aiming to add value of different natures, through the reintegration of its components or constituent materials to the production cycle.

As a theoretical-conceptual basis, the study uses a discussion about the environment, public policies and the scope of reverse logistics, analyzing the strategies for structuring the recycling chain. The research adopted is exploratory, with the application of different strategies for data collection, involving secondary sources produced by public agencies, specialized institutions and the media. The results show that the multiple actors involved in the whole process of the reverse PET chain, whether public or private, cannot individually organize themselves to achieve the desired operational and environmental effectiveness in the city of Manaus, despite the increase in the volume of recycling. The achievement of good results depends, above all, on investment at both ends of the reverse chain: in selective collection and in the market for the recycled product, going through alternative solutions that promote cultural change in the riverside communities in the sense of reeducating them in the use and correct disposal of PET bottles.

KEYWORDS: Reverse Logistics, PET Packaging, Environmental Impact, Environment.

\section{INTRODUÇÃO}

O estudo dos dados do Compromisso Empresarial para Reciclagem (CEMPRE), associação sem fins lucrativos dedicada à promoção da reciclagem dentro do conceito de gerenciamento integrado do lixo, indica que a quantidade de garrafas de PET descartadas no leito do rio negro em Manaus, têm contribuído para gerar uma problemática ambiental e de saúde pública grave. Apesar do tratamento feito na água consumida pela população, tem se observado nessa dinâmica, condições favoráveis à proliferação de vetores causadores de doenças, uma vez que a água que os habitantes da cidade consomem provem do rio Negro. Além disso, os peixes, uma das principais fontes de economia da cidade, principalmente das pessoas de baixa renda, vem diminuindo substancialmente na zona urbana de Manaus, fruto 
da falta de oxigênio adequada para a sobrevivência de espécies, em decorrência dos resíduos sólido e em especial, ao alto número de garrafas PETs jogadas no rio diariamente.

A cidade de Manaus possui várias fábricas de envasamento de refrigerantes, sucos, água mineral, mas verifica-se que depois de ter seu líquido consumido, a garrafa de PET é descartada, sendo muitas vezes jogadas direto na natureza, ou colocado em sacos de lixos nas residências, bares, restaurantes, clubes, sacos esses colocados nas calçadas para recolhimento pelas empresas responsáveis, e na maioria das vezes sendo suas embalagens violadas por catadores de lixos ou por animais domésticos. A situação piora quando chove, fazendo com que as embalagens sejam levadas para os ralos, esgotos, provocando entupimento e aumentando o drama da cidade, provocando enchentes e alagamentos com quase sempre perdas materiais e humanas, além de um elevado prejuízo econômico para a cidade e para o estado como um todo.

Em Manaus no ano de 2013, 163 toneladas de lixo reciclável eram coletadas mensalmente, equivalente a apenas $0,17 \%$ de todo o lixo produzido, de acordo com a Secretaria Municipal de Limpeza e Serviços Públicos (SEMULSP).

A atividade de coleta seletiva em Manaus ainda é pequena, mas já alcança um aumento de eficiência, o que influenciou um aumento significativo no índice de recuperação de materiais recicláveis em Manaus, nos últimos 3 anos. De 2013 aos primeiros meses de 2016, a taxa de reciclagem (com base no serviço público de coleta de lixo) saltou de $0,17 \%$ para 3\%.

Em estudo realizado pela pesquisadora do Instituto Nacional de Pesquisas da Amazônia e doutora em Hidroquímica, Hilândia Brandão, sobre a qualidade das águas dos igarapés da cidade, apontou que, com a decomposição do material, são formadas bactérias que consomem oxigênio, produzindo os gases sulfato e sulfeto (INPA, 2006).

Manaus possui três bacias de igarapés: a do Quarenta, a do Mindu e a do Tarumã. A pesquisa do INPA foi realizada considerando a qualidade da água tanto na nascente das bacias, quanto nos pontos principais. Segundo a pesquisadora, com base na análise das águas, foi constatado que as nascentes ainda têm um padrão de qualidade considerável, mas conforme as águas passam pelas áreas onde há maior concentração urbana, vão perdendo qualidade.

O estudo aponta que a Prefeitura oferece apoio logístico e de infraestrutura aos catadores e retira uma vez por semana os resíduos recolhidos pelos Postos de Entrega Voluntária - PEVs, levando para as associações envolvidas nessa categoria de coleta seletiva. 
A logística é imprescindível para esses trabalhadores que contam com recursos ainda limitados para o transporte do material (CEDOLP/SEMULP-MAO, 2012).

Figura 1 - Igarapé após forte chuva - zona periférica de Manaus

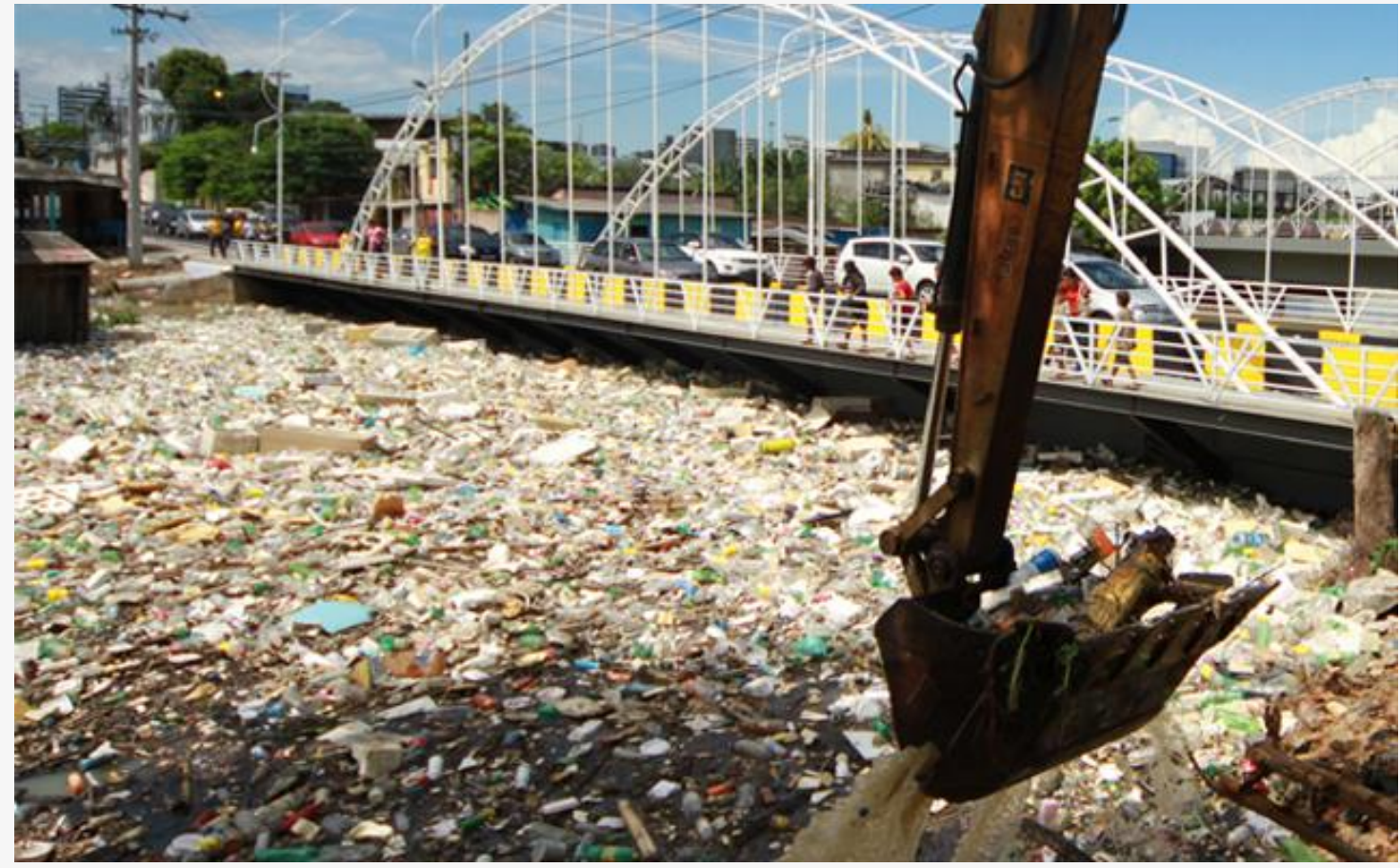

Fonte - Paulo Rinaldi

Grande parte do resíduo sólido retirado dos igarapés vai parar no aterro sanitário da cidade, inclusive o material que poderia ser reciclado. A pesquisa desenvolvida constatou que a Secretaria Municipal de Limpeza e Serviços Públicos (SEMULSP), não investe no reaproveitamento pois decidiu focar no combate à origem do problema que, segundo ela, é a educação ambiental da população. A SEMULSP utiliza duas escavadeiras hidráulicas para retirar o lixo dos 44 igarapés da capital. O equipamento não consegue separar o lixo coletado. Também não há equipes, dentro da Secretaria, que trabalhe na coleta seletiva dos resíduos. O ideal é que as pessoas não joguem lixo nos igarapés, por isso as ações da Secretaria são no sentido de mudar o conceito da população. O trabalho de reciclagem não é simples e depende do esforço das empresas que atuam no ramo. (Secretaria Operacional de Limpeza Pública/SEMULSP, 2016).

A proposição de ações integradas que contribuam para a geração de renda e destinação adequada de recursos "inservíveis", como é o caso das garrafas PET lançadas na orla urbana 
da cidade, é justificada do ponto de vista econômico e ambiental, em função dos danos decorrentes de sua destinação inadequada.

Uma das possibilidades viáveis seria a implantação real da Política Nacional dos Resíduos Sólidos visando buscar uma solução mais eficiente para a reciclagem das garrafas PET pós consumo e tratá-la como uma logística reversa das embalagens e apropriar as responsabilidades a todos os atores envolvidos diretamente ou indiretamente no problema.

Dentro deste contexto, o objetivo principal deste trabalho é, a partir de análise e estudo sobre o tema, propor soluções viáveis para o enfretamento deste grave problema social e ambiental na cidade de Manaus: a grande quantidade de garrafas de PETs depositadas na orla urbana todos os dias, sem uma destinação ambientalmente correta.

\section{EMBASAMENTO TEÓRICO}

\section{Logística Reversa: um conceito em construção}

A literatura conceitua logística reversa em seu sentido mais amplo, como todas as operações relacionadas com a reutilização de produtos e materiais. Neste artigo, o conceito de logística reversa se concentrará no exame dos fluxos reversos, ou seja, naqueles que fluem no sentido inverso ao da cadeia direta, a partir dos produtos descartados, após seu consumo, visando agregar valor de diversas naturezas, por meio da reintegração de seus componentes ou materiais constituintes ao ciclo produtivo (KRIKKE et al., 2003). Logística Reversa trata dos fluxos reversos dos produtos, é o gerenciamento do fluxo de materiais do seu ponto de consumo até seu ponto de origem. Segundo Chaves e Martins apud Costa (2006, p.4) "o processo gerencial da Logística Reversa é responsável por tornar possível o retorno de materiais e produtos, após sua venda e consumo a seus centros produtivos e de negócios, por meio de canais reversos de distribuição, agregando valores aos mesmos".

A aprovação da lei No 12.305/2010 - Política Nacional dos Resíduos Sólidos (PNRS) surge como um reforço ao processo de reciclagem no Brasil, dando suporte legal e incentivo a esta crescente atividade no país. Esta lei constitui a Política Nacional dos Resíduos Sólidos, que entre seus decretos determina a logística reversa: 
XII - Instrumento de desenvolvimento econômico e social caracterizado por um conjunto de ações, procedimentos e meios destinados a viabilizar a coleta e a restituição dos resíduos sólidos ao setor empresarial, para reaproveitamento, em seu ciclo ou em outros ciclos produtivos, ou outra destinação final ambientalmente adequada (BRASIL, 2010).

\section{O Politereftalato de Etileno - PET}

O Politereftalato de Etileno, mais conhecido como PET, é um tipo de plástico muito utilizado na fabricação de garrafas (de refrigerantes, água, sucos, óleos e etc.) e de alguns tipos de tecidos. Do ponto de vista químico, o PET é um polímero termoplástico. Uma das grandes vantagens do PET é que ele pode ser reprocessado várias vezes, facilitando e favorecendo seu processo de reciclagem e uso contínuo na cadeia produtiva.

Segundo Mueller (2005) apud Castro, Ferreira e Souza (2012): O ciclo dos produtos na cadeia comercial não termina quando os mesmos são descartados pelos consumidores, a reciclagem e reaproveitamento dos materiais se tornou foco no meio empresarial, estimulando a responsabilidade da empresa sobre o fim da vida de seu produto.

A utilização das garrafas de PET, vem conquistando novos mercados, como o mercado dos óleos vegetais, sucos, chás, bebidas isotônicas, ampliação do mercado de águas e outros. Este crescimento vertiginoso, juntamente com o desenvolvimento de novas tecnologias na área petroquímica, tornou o sistema de produção das resinas de PET implantado no Brasil obsoleto, que não conseguiu competir com os preços internacionais. Hoje a produção desta resina esta localizada no estado de Pernambuco, produzida por uma empresa italiana que praticamente supre a necessidade do mercado nacional.

As informações sobre as resinas virgens de PET, não são muitos transparentes e também os preços praticados, devido a legislação brasileira não permitir o uso de material reciclado em alimentos, portanto não sabemos quanto dessas resinas estão sendo importadas, ou quanto é o material reciclado industrialmente, ou quanto efetivamente foi utilizado para fabricação de garrafas para alimentos, nem mesmo os números dos índices de reciclagem são precisos, simplesmente, utilizados como referencias ( $10^{\circ}$ Censo da ABPET, 2016). 


\section{DESENVOLVIMENTO DA TEMÁTICA}

\section{Reciclagem de Garrafas PET Pós Consumo}

Figura 2 - Catador de PET no Rio Negro

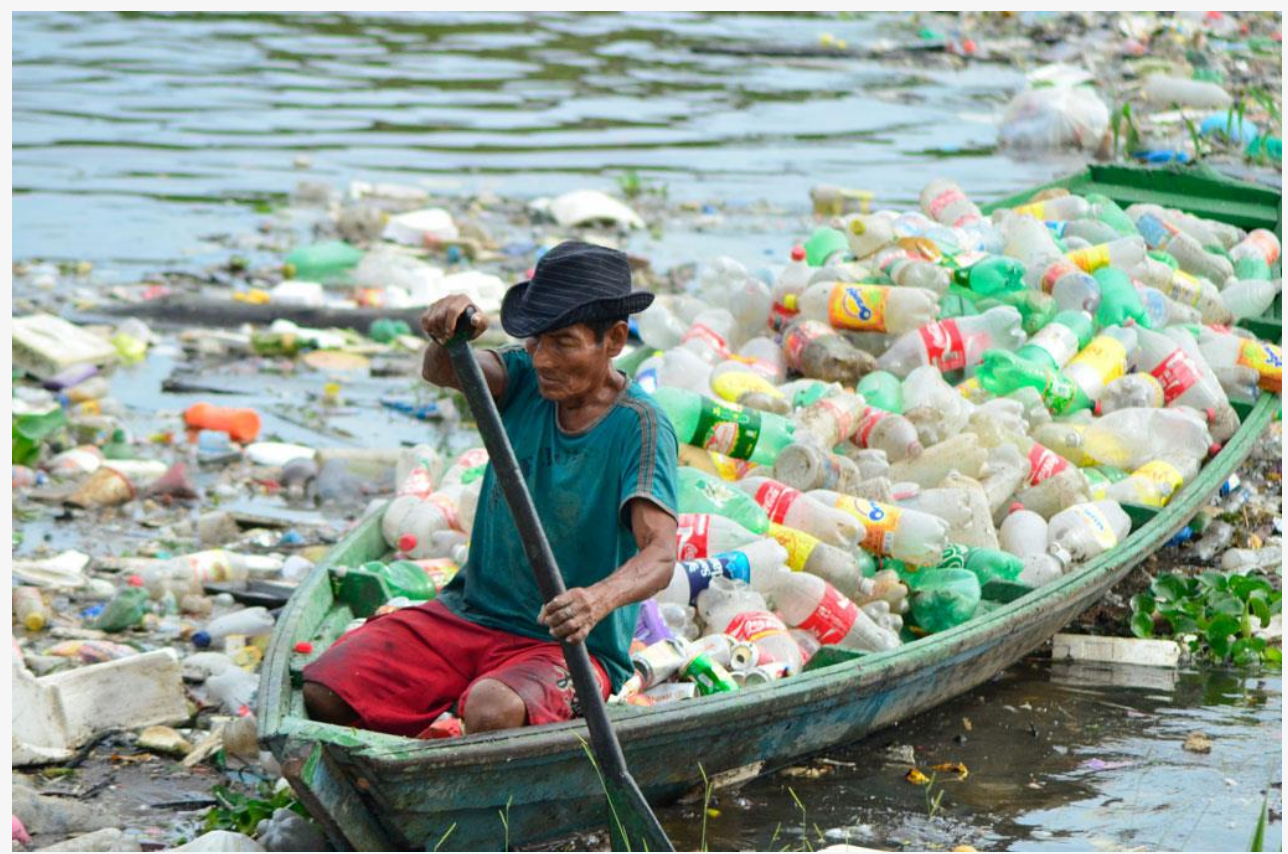

Fonte - Prefeitura de Manaus-semmas.manaus.am.gov.br

As garrafas de PET começaram a ser utilizadas no Brasil no inicio da década de 1990, no envase de refrigerantes e águas minerais. Havia na época 02 (dois) fabricantes de resinas PET, uma pertencente a Rhodia, no estado de São Paulo e outra em Camaçari, na Bahia. O grupo baiano foi quem inicialmente importou a resina de PET para injeção das pré-formas (parison), em Manaus.

O sucesso da substituição das embalagens de vidro, principalmente das embalagens de refrigerantes na época chamada de "embalagens família", foi tão grande, que rapidamente conquistou o mercado, gerando uma falta de matéria prima no mercado nacional, necessitando importar essa resina dos mercados da Argentina e Coreia do Sul (ABIPLAST, 2006).

A experiência dos grupos internacionais em seus países, como a Rhodia (França) e a Coca-Cola (Estados Unidos), já se antecipavam naquele momento ao sucesso dessa nova embalagem, em uma ação visionária criaram uma espécie de verticalização (hoje chamada de responsabilidade estendida), para o problema que viria a ocorrer, que era o da RECICLAGEM 
destas embalagens. Neste sentido, foram criadas algumas recicladoras, aproveitando a estrutura já existente de coleta e separação dos materiais recicláveis feitas pelos sucateiros e associações de catadores e dos trabalhadores dos lixões. Também um órgão representativo chamada de Associação Brasileira da Indústria do PET (ABIPET), com a função de divulgar e promover o consumo das resinas de PET e também a incentivar a reciclagem da mesma.

A própria $\mathrm{ABIPET}$ promove uma divulgação dos resultados anuais do consumo de material virgem para utilização em garrafas de PET, e também um censo sobre a evolução da reciclagem no Brasil e no mundo, atualmente em sua $10^{\mathrm{a}}$ edição.

Em um levantamento histórico sobre a reciclagem destas embalagens, verificou-se que desde o seu início, a única medida eficaz tomada para o aumento da quantidade de material reciclado, foi a introdução da prensa hidráulica para enfardar as garrafas e aumentar a sua densidade aparente. Medida que favoreceu os catadores que formavam as associações e os catadores independentes que vendiam seus materiais aos sucateiros.

O enfardamento permitiu diminuir drasticamente o frete do material a ser reciclado e este ganho financeiro, parte foi repassado aos catadores, praticamente dobrando o preço do material a ser reciclado . Também a criação das cooperativas pelas prefeituras auxiliaram a melhorar o índice de reciclagem nos últimos anos.

O estudo dos dados da Secretaria Municipal de Limpeza e Serviços Públicos (SEMULSP), comprova que em Manaus, 163 toneladas de lixo reciclável são coletadas mensalmente, equivalente a apenas $0,17 \%$ de todo o lixo produzido.

Por falta de indústrias de processamento de resíduos, boa parte deste insumo acaba sendo enviado ao Sudeste para o reaproveitamento ou retorna para o lixo comum, como é o caso do vidro.

Segundo o diretor executivo da associação Compromisso Empresarial para Reciclagem (CEMPRE), André Vilhena, é preciso investir em políticas públicas para atrair investidores.

"Uma forma de se fazer isso é revisando os tributos que incidem na cadeia. O reciclador carrega $32 \%$ da carga tributária sobre um material que é lixo, o que não faz sentido", contesta. 
De acordo com Vilhena, o potencial de mercado de processamento de recicláveis é enorme em Manaus, devido ao Polo Industrial, que tanto produz resíduos como material reciclado, especialmente plástico e papel.

A Ambev, por exemplo, utiliza $75 \%$ de resíduos recicláveis na composição de suas garrafas e desenvolveu, no ano passado, uma PET que pode ser $100 \%$ reciclada.

O estudo aponta, que a questão da destinação correta dos resíduos precisa ser enfrentada pelos múltiplos agentes envolvidos na cadeia.

\section{Desafios da Coleta Seletiva}

Segundo dados do CEMPRE, existem em Manaus três indústrias de processamento de resíduos, uma de plástico, outra de papel e uma de baterias.

Estudos comprovam que desde 2005, o programa de coleta seletiva da prefeitura de Manaus garante, todos os meses, por meio da Secretaria Municipal de Limpeza Urbana (SEMULSP), cerca de $\mathrm{R} \$ 500,00$ à 22 catadores de material reciclável, que, anteriormente, atuavam de forma irregular no aterro municipal e ainda sujeitos à contaminação por doenças e renda incompatível com o serviço praticado.

Com o programa, os catadores ganharam a responsabilidade de separar e comercializar o "lixo limpo" - papéis, vidros, plásticos e metais. No início do programa, a média de suas rendas mensais era $\mathrm{R} \$ 186$ e a quantidade de lixo coletado não chegava 55 toneladas, segundo a prefeitura. Hoje, a marca da coleta seletiva é de 1.446 .162 toneladas. Para tanto, os catadores passaram por treinamentos que possibilitaram sua preparação a fim de receber todo material recolhido pelo Programa Coleta Seletiva, permitindo um crescimento de $165 \%$ no percentual praticado em Manaus (SEMULSP, 2008).

O estudo detectou que ao contar com esses "catadores", além da prefeitura ganhar um suporte específico para fazer a coleta seletiva, diminuiu significativamente a permanência desorientadas desses catadores nos lixões da cidade e permitiu a promoção da inclusão social e a geração de rendas dessas pessoas. 
Neste processo, o lixo é coletado pela SEMULSP e entregue aos catadores para que seja feita a devida separação. Depois de concluída a seleção dos materiais que possam ser comercializados, a prefeitura transporta para o aterro o que não é de interesse dos catadores.

De acordo com estudos, os pontos de entrega voluntária (PEV) são os principais modelos de coleta seletiva em Manaus. Trata-se de quiosques espalhados pela cidade que recebem o lixo de forma separada. Se o morador não conseguiu, em seu bairro, deixar o lixo limpo no caminhão coletor da coleta seletiva pode deixar esse material em um desses quiosques, que são gerenciados por cooperativas de catadores.

Neste processo, já que a destinação final dos resíduos sólidos de Manaus, que era um problema antigo e grave na cidade, foi contornada em parte pela coleta seletiva, que cresceu $70 \%$ desde 2005.

\section{O Mercado}

Dentre as empresas pertinentes à reciclagem, a empresa COPLAST atua com reciclagem de resíduos plásticos industriais em Manaus há 35 anos e atualmente, emprega 677 trabalhadores e recicla 60 tipos de plásticos gerados nas indústrias do Polo Industrial de Manaus. A empresa também atua com terceirização de serviços de logística reversa.

O estudo revela, segundo a Figura 2, que a reciclagem de embalagens de PET só vem crescendo ao das últimas décadas.

Figura 3 - Material reciclado em atividades industriais -Brasil (\%)

\begin{tabular}{|l|c|c|c|c|c|c|c|c|c|}
\hline $\begin{array}{c}\text { Atividades Industriais/ } \\
\text { ano }\end{array}$ & $\begin{array}{r}\mathbf{1 9} \\
\mathbf{9 5}\end{array}$ & $\begin{array}{r}\mathbf{1 9} \\
\mathbf{9 7}\end{array}$ & $\begin{array}{c}\mathbf{1 9} \\
\mathbf{9 9}\end{array}$ & $\begin{array}{c}\mathbf{2 0} \\
\mathbf{0 1}\end{array}$ & $\begin{array}{c}\mathbf{2 0} \\
\mathbf{0 3}\end{array}$ & $\begin{array}{c}\mathbf{2 0} \\
\mathbf{0 5}\end{array}$ & $\begin{array}{c}\mathbf{2 0} \\
\mathbf{0 7}\end{array}$ & $\begin{array}{c}\mathbf{2 0} \\
\mathbf{0 9}\end{array}$ & $\begin{array}{c}\mathbf{2 0} \\
\mathbf{1 1}\end{array}$ \\
\hline Latas de Alumínio & 62,8 & 64,0 & 72,9 & 85 & 89 & 96,2 & 96,5 & 98,2 & 98,3 \\
\hline Papel & 34,6 & 36,3 & 37,9 & 41,4 & 44,7 & 46,9 & 43,7 & 46 & 45,5 \\
\hline Vidro & 35,0 & 39,0 & 40,0 & 42 & 45 & 45 & 47 & 47 & 47,0 \\
\hline Embalagens PET & 25,4 & 16,2 & 20,4 & 32,9 & 43 & 47 & 53,5 & 55,6 & 57,1 \\
\hline
\end{tabular}

Fonte - Associação Brasileira de Alumínio - ABAL; Associação Brasileira de Papel e Celulose - BRACELPA; Associação Técnica Brasileira de Indústrias Automáticas de Vidro - ABIVIDRO; Associação Brasileira da Indústria do PET - BIPET; Compromisso Empresarial para Embalagem - CEMPRE. 
A cidade de Manaus já apresenta uma Cooperativa que fabrica vassouras a partir de embalagens PET: a Eco Recicla. Além da Cooperativa Eco Recicla, existem mais 19 bases distribuídas em diversos bairro em Manaus que fazem a coleta desse material. O estudo efetuado constata que o maior desafio enfrentado consiste na logística de transportar o material coletado de seus bairros até a Cooperativa Eco Recicla. Torna-se um processo moroso, pois, apesar de existirem dois caminhões, muitos trabalhadores moram em locais de difícil acesso onde o caminhão não consegue chegar. Além disso, ainda há problemas técnicos nos caminhões que muitas vezes ficam impossibilitados de fazer o transporte devido à falta de manutenção dos mesmos, uma vez que a manutenção destes é sobremodo onerosa.

Outro mercado em expansão em Manaus é a fabricação de telhas com PET. Apesar de ser mais cara que a tela de barro comum, mas é muito mais leve, fazendo com que o consumidor economize na parte estrutural do telhado.

\section{RESULTADOS E DISCUSSÃO}

Existe uma clara tendência de que a legislação ambiental caminha no sentido de tornar as empresas cada vez mais responsáveis pelo ciclo de vida de seus produtos. O que significa ser responsável pelo destino de seus resíduos sólidos.

O que realmente sabemos, de uma forma prática é que a quantidade de garrafas PET esta aumentando dia a dia, nos lixos, nos logradouros públicos, nas calçadas, nos rios e lagos e caso não haja uma medida urgente sobre a sua utilização e descarte, muito em breve teremos as consequências que hoje são notícias e manchetes em outros locais no mundo.

Diante de todo o quadro exposto e considerando a relevância do assunto como uma forma de preservação do meio ambiente, sobretudo no caso do rio Negro que entorna a cidade de Manaus, sendo diretamente afetado pela poluição ambiental produzida pelas garrafas pets jogadas em seu leito e ainda sem deixar de contemplar a realidade social, econômica, geográfica e sobretudo cultural da população de Manaus, principalmente as que moram e vivem nas margens do rio são elencadas algumas propostas de solução para o grave problema da reutilização das garrafas pets em Manaus, conforme a seguir enumerados:

1. Separação de todos os componentes, dando destinação correta aos resíduos reutilizados e não-reutilizados, encaminhamos para empresas recicladoras que trabalham especificamente com cada um deles; 
2. Transformar lixo produzido pelas garrafas pets em matéria-prima, empregos, capacitação e educação ambiental;

3. Desenvolvimento por parte do governo de programas de Responsabilidade socioambiental focados em três pilares: econômico, social e ambiental.

4. Estudo de impacto ambiental pelas agencias de governo e iniciativa privada com propostas economicamente viáveis com foco na sobrevivência do rio e das populações que dele depende.

5. Criação por parte do governo de uma usina de resíduos sólidos próprias para o manejo e reutilização de garrafas pets na cidade de Manaus, no contexto de PPP, já que seu custo é muito alto para ser atendida somente pela iniciativa privada, dentro da visão da logística reversa, além da ampliação e fortalecimento das oficinas de reciclagens já existentes;

6. Desenvolver programas de governo, visando mecanismos de integração entre catadores de lixo, iniciativa privada e sociedade em geral visando solucionar esse grave problemas social e ambiental na cidade de Manaus.

7. Desenvolver e auxiliar no processo de reciclagem de materiais, buscando dar destino adequado a estes resíduos, desta forma contribuindo junto com os coletores lhe proporcionando uma vida mais digna, e visando o meio ambiente, tirando os resíduos que as garrafas pets podem produzir, comprometendo o meio onde se encontra.

8. Desenvolver um trabalho de conscientização na sociedade manauara com o objetivo de demonstrar uma perspectiva de quão viável pode ser a reciclagem de materiais secos e húmidos, como é o caso de garrafas de PETs, e quão benéficos podem ser seus resultados, implicando no meio social e meio ambiental, e como pode ser rentável esse tipo de atividade para a sociedade amazonense como um todo.

9. Fabricação de uma estação de tratamento de efluentes biológicos ou químicos, compacta, usando produtos recicláveis como pet ou garrafas plásticas. Reator anaeróbio conjugado com tanque de decantação a base de resina poliéster e filtro anaeróbio a base de garrafas de PET. Essa Estação de Tratamento de Efluentes - ETE pode, além de outros, tratar os efluentes biológicos no âmbito residencial, como residências de baixo, e auto padrões, prédios comerciais shopping centers, pequenas e grandes indústrias postos de gasolinas e entidades governamentais.

Deve-se buscar elaborar um plano de coleta, definindo equipamentos e periodicidade de coleta dos resíduos. A regularidade e eficácia no recolhimento dos materiais são importantes para que a população tenha confiança e se disponha a participar. 
Finalmente, é necessária a instalação de um centro de triagem para a limpeza e separação dos resíduos e o acondicionamento para a venda do material a ser reciclado. Também é possível implantar programas especiais para reciclagem de entulho (resíduos da construção civil).

\section{CONSIDERAÇÕES FINAIS}

Os resultados apontam que os múltiplos atores envolvidos em todo processo da cadeia reversa do PET e do avanço no volume de reciclagem, nenhum dos setores, seja público ou privado, consegue individualmente organizar-se para o alcance da efetividade operacional e ambiental desejável no cenário brasileiro, sobretudo na cidade de Manaus. Assim, objetiva-se desenvolver ações integradas por parte do governo, iniciativa privada e sociedade em geral voltadas à criação e aplicação de políticas públicas voltadas a destinação correta das garrafas pets inservíveis, principalmente na zona urbana da cidade. $\mathrm{Na}$ proposição de se gerar alternativas adequadas e geração de fontes de rendas alternativas as comunidades locais e regionais a fim de mitigar os impactos negativos das garrafas de PETs descartadas no rio Negro.

\section{REFERÊNCIAS}

CASTRO, D. da S., FERREIRA, R. S. A., SOUZA, D. N. F. Logística Reversa na Amazônia: Análise da Produção Artesanal de Vassouras de Garrafas PET's em uma Cooperativa na Cidade de Manaus. Anais do XV Simpósio de Administração da Produção e Operações Internacionais - SIMPOI, de 28 a 31.08.2012, São Paulo, SP, 2012.

CASTRO, M. Gestão de resíduos sólidos na região metropolitana de Manaus: municípios de Iranduba, Manacapuru e Novo Airão - AM. 2011. 25f. Projeto de Dissertação - Programa de Pós-Graduação em Ciência do Ambiente e Sustentabilidade na Amazônia - PPGCASA, Universidade Federal do Amazonas, Manaus.

CIDADE, F. C. A Rede de Comercialização de Materiais Recicláveis na Cidade de Manaus Amazonas. Manaus: ANINC - Anuário do Instituto de Cultura e Natureza, Universidade Federal do Amazonas, 2014. 
CIDADE, F. C. Lixo ao luxo: a comercialização dos materiais recicláveis e o depósito final dos resíduos sólidos nas cidades de Tabatinga, Tefé e Parintins. In XIV Encuentro de Geógrafos de Améria Latina - EGAL, 2013, Lima. XIV Encuentro de Geógrafos de América Latina 2013 - Peru, 2013.

Disponível em http://g1.globo.com/am/amazonas/noticia/2014/07/sem-coleta-seletiva-lixoretirado-dos-igarapes-de-manaus-vai-para-aterro.html Acessado em 23 de fevereiro de 2017. Disponível em http://new.d24am.com/amazonia/meio-ambiente/falta-empresasespecializadas-017-lixo-reciclado-manaus/88101 Acessado em 23 de fevereiro de 2017.

Disponível em http://new.d24am.com/amazonia/meio-ambiente/falta-empresasespecializadas-017-lixo-reciclado-manaus/88101 Acessado em 24 de fevereiro de 2017.

GONÇALVES-DIAS, S.L.F., Há vida após a morte: um (re)pensar estratégico para o fim da vida das embalagens. $5^{\text {a }}$ ed. Porto Alegre/SC: Bookman, 2006.

GONÇALVES-DIAS, S.L.F., TEODÓSIO, A.S.S., Estrutura da cadeia reversa: “caminhos” e "descaminhos" da embalagem PET. EAESP-FGV, Produção, v. 16, n. 3, p. 429-441, Set./Dez. 2006.

GONÇALVES-DIAS, S.L.F., TEODÓSIO, A.S.S., Reciclagem do PET: desafios e possibilidades. XXVI ENEGEP - Fortaleza, CE, Brasil, 9 a 11 de Outubro de 2006.

LEITE, P. R. Logística Reversa. Meio Ambiente e Competitividade. São Paulo: Pearson Prentice Hall, 2009. 